\title{
Correction to: Statistical Methods for Global Health and Epidemiology
}

\author{
Xinguang Chen and (Din) Ding-Geng Chen
}

\section{Correction to:}

X. Chen, (Din) D.-G. Chen (eds.),

Statistical Methods for Global Health and Epidemiology, ICSA Book Series in Statistics, https://doi.org/10.1007/978-3-030-35260-8

This book was inadvertently published without appendix in chapters 8 and 13 . The original chapters have been corrected.

The changes in Chapters 8 and 13 caused a change in the page numbers of the subsequent chapters (i.e., Chapters 9-16), but the contents of those chapters remain unchanged.

\footnotetext{
The updated version of these chapters can be found at https://doi.org/10.1007/978-3-030-35260-8_8 https://doi.org/10.1007/978-3-030-35260-8_13 